\title{
Immune and inflammatory biomarkers in cases of bovine perinatal mortality with and without infection in utero
}

\author{
Paulina Jawor, ${ }^{* 1}$ Tadeusz Stefaniak, ${ }^{*}$ and John F. Mee† \\ *Department of Immunology, Pathophysiology and Veterinary Preventive Medicine, Wroclaw University of Environmental and Life Sciences, \\ 31 C.K. Norwida St., 50-375 Wroclaw, Poland \\ †Animal and Bioscience Research Department, Teagasc, Moorepark Research Centre, Fermoy, Co. Cork, Ireland
}

\begin{abstract}
The objective of this study was to compare acutephase protein [serum amyloid A (SAA) and haptoglobin $(\mathrm{Hp})]$ and immunoglobulin $\mathrm{G}_{1}$ and $\mathrm{M}$ concentrations in blood plasma of cases of bovine perinatal mortality due to infection in utero or traumotocia and in unexplained cases. Plasma samples were collected from 110 stillborn calves with bacterial infection (INF_B, $\mathrm{n}=16$ ), with viral or parasitic infection ( $\mathrm{INF}_{-} \mathrm{V} / \mathrm{P}, \mathrm{n}=31$ ) during pregnancy, with lesions of fatal traumotocia (TRAUM, $\mathrm{n}=22$ ), and from unexplained deaths (UNEXPL, $\mathrm{n}=$ 41). Plasma immunoglobulin and SAA concentrations were measured by ELISA, and Hp concentrations were measured by the guaiacol method and ELISA. Concentrations of SAA in the INF_B group were higher than in the UNEXPL group and tended to be higher than in the INF_V/P group. A reference range $(0-29 \mathrm{mg} / \mathrm{L})$ was established for SAA in stillborn calves. Concentrations of $\mathrm{Hp}$ tended to be higher in the INF_B group compared with INF_V/P group. Concentrations of IgM tended to be higher in the INF_B group compared with the TRAUM and INF_V/P groups. Concentrations of $\operatorname{IgG}_{1}$ were numerically, but not significantly, higher in the INF_V/P and INF_B groups compared with the other groups. The results demonstrate upregulation of immune and inflammatory responses in stillborn calves exposed to bacterial infection in utero. The immuneinflammatory parameters did not differ between calves with viral or parasitic infections and traumotocia. These immune-inflammatory profiles did not contribute to the diagnosis of unexplained stillbirth. This is the first report of an elevated acute phase protein response in stillborn calves. Measurement of SAA and IgM concentrations may be used in the diagnosis of bacterial infections in stillborn calves.
\end{abstract}

Received August 4, 2016.

Accepted October 10, 2016.

${ }^{1}$ Corresponding author: paulina.jawor@up.wroc.pl
Key words: bovine, stillbirth, acute phase proteins, in utero infection

\section{INTRODUCTION}

Bovine perinatal mortality may be defined as calf death at full-term pregnancy $(\geq 260 \mathrm{~d})$, before, during, or within $48 \mathrm{~h}$ of calving (Berglund et al., 2003; Mee et al., 2014). Herd-level perinatal mortality rates vary between 0 and $30 \%$, with median values between approximately 4 and 7\% (Fourichon et al., 2001; Mee et al., 2008). In recent years, high and increasing perinatal mortality rates have been reported internationally, particularly in Holstein primiparae (Meyer et al., 2001; Berglund et al., 2003; Mee et al., 2008). The significant modifiable and nonmodifiable risk factors associated with bovine perinatal mortality/stillbirth have recently been documented (year of calving, month of calving, plurality, primiparity, previous perinatal mortality, and fetal sex; Mee et al., 2014).

Despite this knowledge about risk factors, stillborn calves remain a diagnostic challenge. The causes of death (COD) in bovine stillbirth vary internationally (Mee et al., 2013) but they may be classified simply as noninfectious and infectious. Multiple COD (co-mortality) and causative agents complicate diagnosis. The most common noninfectious cause of bovine stillbirth is moderate and severe calving assistance (dystocia or traumotocia; Mee and Szenci, 2012; Mee, 2013); even slight calving assistance (but not dystocia) is associated with increased risk of stillbirth (Mee et al., 2008). However, in some studies, dystocia explained only about half of the stillbirths from primiparae (Berglund et al., 2003). This suggests that other non-dystocial factors are associated with bovine stillbirths.

Numerous infectious causes of bovine stillbirth have been documented. Compared with abortion (birth of a non-viable fetus preterm), infection is a less common COD in stillborn calves. Infections account for between 3 and $12 \%$ of stillbirths diagnosed internationally in necropsy studies (Mee, 2013). Infectious agents detected in stillborn calves include Salmonella Dublin, 
Escherichia coli, Aeromonas, Proteus, Streptococcus, Staphylococcus, Neisseria, Absidia, Acinetobacter spp. (Smyth et al., 1992), Corynobacterium pyogenes, Leptospira spp. (Smyth et al., 1992, 1999), Bacillus licheniformis, Mannheimia varigena (Syrjala et al., 2007), Listeria spp., Neospora caninum (Waldner et al., 2010), Salmonella Stanley (Jawor et al., 2013), Coxiella burnetii (Waldner et al., 2010; Muskens et al., 2012), bovine viral diarrhea virus (Smyth et al., 1992), Schmallenberg virus (Bayrou et al., 2014), and bovine herpesvirus 1 and 4 (Kirkbride, 1992; Egyed et al., 2011). It is recognized that some of these isolates are probably contaminants (e.g., Proteus) and others are probably secondary opportunistic infections (e.g., Streptococcus).

In approximately one-third of perinatal mortality cases, no cause of death can be detected (Berglund et al., 2003; Khodakaram-Tafti and Ikede, 2005). The "unexplained stillbirth" is an additional problem for veterinary practitioners and for laboratory diagnosticians. The high rate of unexplained stillbirths in calves may be due in part to the traditionally narrow diagnostic testing menu used in veterinary laboratories. Hence, various physiological markers have been investigated to see whether it is possible to predict stillbirth even if the COD cannot be diagnosed. These included parameters in dams (Kindahl et al., 2002; Kornmatitsuk et al., 2004) and in calves (Kornmatitsuk et al., 2004) to monitor fetal well-being and predict stillbirth. However, these studies had a small number of dams and stillborn animals, limiting their ability to define useful parameters. In addition, although these studies tried to predict the risk of stillbirth, they could not determine the COD as being infectious or noninfectious.

An alternative approach to investigating unexplained stillbirths is to monitor markers of infection as possible predictors of stillbirth. Both circulating neutrophils and immunoglobulins have been studied. High maternal prepartum neutrophil counts predicted the risk of stillbirth in heifers (Chassagne et al., 1999). In cattle, immunoglobulins from the dam do not cross the placenta but the fetus has the ability to produce IgM and IgG after 90 and $111 \mathrm{~d}$ of pregnancy, respectively (Ellis et al., 1978). The older the fetus, the higher the concentrations of IgM and IgG detectable in serum (Sawyer et al., 1973). High serum immunoglobulin concentrations are strong indicators of fetal infection (Ohmann, 1981). For example, serum samples from bovine fetuses experimentally infected with chlamydia, Campylobacter fetus, C. burnetii, bluetongue virus, bovine virus diarrhea virus (BVDV), Anaplasma marginale, and the agents of epizootic bovine abortion had higher IgM and IgG concentrations compared with those of pre- colostral newborn control calves (Sawyer et al., 1973). Calves vaccinated prenatally with $E$. coli from 9 to 102 d before birth took 10 to $14 \mathrm{~d}$ to respond to bacterial antigen administered orally (Conner et al., 1977). In addition to a humoral immune response, intrauterine infection can lead to fetal infection and inflammation. Microorganisms may gain access to the amniotic cavity and fetus by ascending from the vagina and cervix or via hematogenous dissemination through the placenta (transplacental infection). The most common pathway of intrauterine infection is the ascending route (Romero et al., 2003). Microorganisms or their products can stimulate the fetus to produce cytokines and a systemic inflammatory response. In human medicine, this is described as the fetal inflammatory response syndrome (FIRS) and is diagnosed by elevated IL-6 concentration in fetal blood; FIRS is typically diagnosed in preterm fetuses but can also occur in term fetuses (Chaiworapongsa et al., 2002; Bashiri et al., 2006). Human fetuses with FIRS have a higher rate of neonatal complications and are frequently born to mothers with subclinical microbial invasion of the amniotic cavity (Bashiri et al., 2006).

In contrast to human fetuses, little is known about the immuno-inflammatory responses in bovine fetuses. To date, there have been no studies on the acute-phase response in bovine stillborn calves. The acute-phase response is nonspecific and it develops after any disturbance of homeostasis, but particularly inflammation. The body mounts a multifactorial response to remove and replace damaged tissue. One of the mechanisms involved is the production and secretion of acute-phase proteins (APP) by the liver (Eckersall and Conner, 1988). In ruminants, testing for APP allows early and precise detection of inflammation. The most common APP measured in cattle are haptoglobin $(\mathbf{H p})$ and serum amyloid A (SAA) (Eckersall and Bell, 2010). The APP have been widely used during monitoring of treatment (Smith et al., 1998; Jawor et al., 2008), as an objective parameter for detecting sick animals (Gruys et al., 1993; Deignan et al., 2000), monitoring of calf group health (Gånheim et al., 2007; FurmanFratczak et al., 2011), or as a tool to estimate the safety of repeated liver biopsy (Vels et al., 2009; Jawor et al., 2016). To date, there are no published studies about APP in stillborn calves.

The hypothesis tested in this study was that in cases of perinatal bovine mortality, where infection is present, there will be increased concentrations of fetal circulatory immunoglobulins and APP. Two sub-hypotheses were tested: (1) that the magnitude of the fetal immuno-inflammatory response may differ depending on the type (bacterial, viral, parasitic) of infection, and (2) 
that lower, but detectable, concentrations of immunoinflammatory biomarkers may be found in cases of traumotocia due to trauma-induced inflammation and in "unexplained stillbirths" due to undiagnosed infections. Hence, the objective of this study was to compare immuno-inflammatory biomarkers APP (Hp and SAA) and immunoglobulins $\left(\mathrm{G}_{1}\right.$ and $\mathrm{M}$ classes) in cases of bovine perinatal mortality diagnosed with intrauterine infection or traumotocia or in unexplained cases.

\section{MATERIALS AND METHODS}

\section{Calves}

In total, 110 calves were selected from a database of bovine perinatal mortality $(\mathrm{n}=698 ; 0-48 \mathrm{~h}$ old $)$ necropsy cases from Irish dairy farms over 3 yr (20112013). The case inclusion criteria were full-term $(\geq 260$ $\mathrm{d}$ of gestation), died within $1 \mathrm{~h}$ of birth (on average, 3 min old, varying from 0 to $60 \mathrm{~min}$ ), but did not consume colostrum. Calves were either Holstein-Friesian ( $\mathrm{n}=47)$ or Holstein-Friesian or Jersey crossbreds ( $\mathrm{n}=$ 63; Aberdeen Angus, Belgian Blue, Holstein-Friesian, Jersey, Norwegian Red, or Swedish Red sires).

\section{Necropsy and Laboratory Examinations}

All carcasses were subjected to systematic external and internal gross examinations and sampling for microbiology and immune-inflammatory biomarkers by the same pathologist. The calving or death to necropsy (sampling) interval was, on average, $28 \mathrm{~h}$, and varied between 3 and $75 \mathrm{~h}$. Ear biopsies were collected using tissue tags and individually tested for BVDV by antigen ELISA (HerdChek BVDV* Ag/Serum Plus, Idexx Europe B.V., Hoofddorp, the Netherlands). Abomasal contents were aseptically collected into a Vacutainer (Becton Dickinson, Plymouth, UK) and inoculated onto $5 \%$ blood agar, Brucella agar, Campylobacter agar, and Sabouraud dextrose plates and incubated at $37^{\circ} \mathrm{C}$ in $8 \%$ $\mathrm{CO}_{2}$. In addition, abomasal contents were aerobically cultured on xylose lysine deoxycholate (XLD) agar at $37^{\circ} \mathrm{C}$ and examined for Salmonella spp. Fetal blood was collected using a 10-mL syringe into a heparinized Vacutainer (LH 170 IU, BD Vacutainer, Becton Dickinson), centrifuged $\left(2,000 \times g, 10 \mathrm{~min}, 4^{\circ} \mathrm{C}\right)$, and the plasma was stored at $-20^{\circ} \mathrm{C}$. The degree of plasma hemolysis was visually evaluated as follows: no or very slight $(\mathrm{n}=39$ samples $)$, moderate $(\mathrm{n}=65)$, and significant $(\mathrm{n}=6)$. Plasma was tested for antibodies to Neospora caninum and to Schmallenberg virus (SBV) using a Neospora ELISA (IS IVET Bovine Serum
Neospora Caninum LSI-ELISA, Laboratoire Service International, Lissieu, France) and an SBV ELISA (ID Screen Schmallenberg Virus Indirect ELISA, ID.vet, Montpellier, France), respectively.

Plasma was analyzed for SAA by a multispecies ELISA (TP 802, Tridelta Development, Maynooth, Ireland) with intra- and interassay coefficients of variation (CV) of 13.6 and $11.3 \%$, respectively, and a detection limit of $9.4 \mathrm{mg} / \mathrm{L}$. Plasma haptoglobin was determined either by the microplate guaiacol method [measuring peroxidase activity of haptoglobin-hemoglobin (Hp-Hb) complex] (for 84 samples with no or moderate degree of hemolysis) or by ELISA (\#2410-7 Life Diagnostics Inc., Knypersley, UK) (for 26 samples with no, moderate, or significant degree of hemolysis). The Hp guaiacol intraand interassay CV were 4.3 and $11.2 \%$, respectively. The Hp ELISA intraassay CV was $8.4 \%$ and, as only one plate was used, no interassay $\mathrm{CV}$ was calculable. Hemolysis interferes with the guaiacol method; however, the guaiacol and ELISA methods are highly correlated ( $\mathrm{r}=0.97$; Cooke and Arthington, 2012). The guaiacol method (Jones and Mould, 1984) was performed with standard serum from Tridelta Development (TP801CAL) to generate the standard curve. The detection limit was $50 \mathrm{mg} / \mathrm{L}$ (detection limit of $15.6 \mathrm{mg} / \mathrm{L}$ in the ELISA). Plasma immunoglobulin concentration was determined by ELISA (E10-101, E10-116, Bethyl Laboratories, Montgomery, TX). The intra- and interassay $\mathrm{CV}$ for IgM was 6.9 and $8.9 \%$ and for $\mathrm{IgG}_{1}$ was 10.0 and $7.1 \%$, respectively. The limits of detection for IgM and $\mathrm{IgG}_{1}$ were 39.05 and $54.67 \mathrm{mg} / \mathrm{L}$, respectively.

\section{Diagnostic Groups}

Four mutually exclusive diagnostic groups were compared, 2 infection groups: bacterial (INF_B; $\mathrm{n}=16$ ) and viral or parasitic infection of calves in utero $\left(\mathbf{I N F} \_\mathbf{V} / \mathbf{P} ; \mathrm{n}=31\right)$ and 2 control groups: traumotocia (TRAUM; n $=22$ ) and unexplained death (UNEXPL; $\mathrm{n}=41$ ). Diagnosis of infection was made only in calves, not their dams. The case inclusion criterion for the INF_B group was detection in pure or nearly pure growth of one of the following primary fetopathogens: Bacillus licheniformis (5 cases), Salmonella Dublin (7 cases), Trueperella pyogenes (3 cases), or Listeria monocytogenes (1 case). The case inclusion criterion for the INF_V/P group was diagnosis of the following fetal infections: BVDV (7 cases) or Neospora caninum (6 cases) as outlined above, or Schmallenberg virus fetopathy (18 cases) by the EFSA criteria (EFSA, 2013; 2 or more of the following malformations: arthrogryposis, hydranencephaly, torticollis, kyphosis, 
scoliosis, or brachygnathia inferior) with the presence (9 cases) or absence of fetal SBV antibodies. The case inclusion criteria for the TRAUM group were detection of severe antemortem lesions (hemorrhage at the lesion site) consistent with iatrogenic parturient trauma at assisted calvings: fractured spine/vertebral luxation, fractured ribs (costal and costo-chondral junctions), fractured mandible, limb fractures, moderate and severe subcutaneous thoracic and limb hemorrhages/ bruising, hemoarthrosis, hepatic rupture, moderate and severe hemoperitoneum, diaphragmatic hernia, or polytrauma. The case inclusion criteria for the UNEXPL group were failure to meet the inclusion criteria of the other 3 groups and where the cause of death was undetermined. This was a diagnosis of exclusion in the absence of assignable cause of mortality with no detectable lesions; that is, "idiopathic stillbirth." Once calves met these mutually exclusive inclusion criteria, they were selected based on sufficient plasma sample available $(>100 \mu \mathrm{L})$ for analysis and the least degree of blood sample hemolysis, as assessed visually.

\section{Statistical Analysis}

Statistical analyses were conducted using Statistica 12.5 (StatSoft Inc., Tulsa, OK). Data were checked for normality using the Shapiro-Wilk test. As data for each analyte were not normally distributed, even after logarithmic transformation $\left(\log _{10}\right)$, the groups were compared by nonparametric analysis. The ranked group values were analyzed using the Kruskal-Wallis ANOVA with a Bonferroni adjustment for post hoc multiple comparisons when differences between paired groups were significant $(P<0.05)$. The odds ratios were calculated according to Altman (1991). For clarity, means and standard errors of the nontransformed data are presented. In addition, the frequencies of cases above and below the normal threshold values for each analyte were compared between groups by Pearson's chi-squared analysis. Statistical, tendency, and numerical differences were defined by $P$-values of $<0.05,<0.1$ but $>0.05$, and $>0.1$, respectively.

Initially, both infection groups were combined and compared with the other 2 groups, and then the former were disaggregated into the 2 infection groups for further analyses. Because of the limited number of cases within individual infection type within groups, intragroup biomarker profile comparisons were not carried out. Normal ranges for each analyte except SAA (which has no published reference range for newborn calves) were sourced from the peer-reviewed literature: Hp $<100 \mathrm{mg} / \mathrm{L}$ from Richter (1974); IgM $<110 \mathrm{mg} / \mathrm{L}$ and $\mathrm{IgG}_{1}<160 \mathrm{mg} / \mathrm{L}$ from Sawyer et al. (1973).
A logistic regression model with nonlinear estimation Rosenbrock and quasi-Newton method was used to evaluate which variable - SAA, Hp, IgM, or $\mathrm{IgG}_{1}$ - would be a predictor to discriminate bacterial infection from other COD categories. A receiver operating characteristic (ROC) analysis was performed to evaluate the ability of predictor variables to discriminate between bacterial infection and other COD. The sensitivity (Se) versus 1 minus specificity $(\mathbf{1}-\mathbf{S p})$ over all possible threshold values of the parameters was plotted. The optimal cut-off point was defined based on the Youden index $[J=\max (\mathrm{Se}+\mathrm{Sp}-1)]$, which maximizes Se and Sp across various cut-off points, and the cut off with the highest $J$ is selected. The optimal cut-off value for diagnosis of bacterial infection was determined where possible for each analyte.

\section{RESULTS}

\section{Comparisons Between Groups}

We detected no significant differences in SAA, Hp, $\mathrm{IgG}_{1}$, or IgM concentrations between calves infected in utero (INF_B and INF_V/P combined) and calves that died due to traumotocia or unexplained causes. After splitting the infection category into INF_B and INF_V/P groups, SAA concentrations were significantly higher in the INF_B group than in the UNEXPL group $(P=0.04)$ and tended to be significantly higher than in the INF_V/P group $(P=0.06)$. Concentrations of Hp tended to be higher in INF_B compared with INF_V/P $(P=0.06)$. Concentrations of IgM tended to be higher in INF_B compared with TRAUM $(P=$ $0.051)$ and $\mathrm{INF}_{-} \mathrm{V} / \mathrm{P}(P=0.09)$. The mean (SEM) values for each biomarker are shown in Table 1 . The mean (SEM) concentrations (mg/L) of SAA, Hp, and IgM were numerically higher in INF_B compared with INF_V/P, TRAUM, and UNEXPL.

\section{Comparisons with Reference Ranges}

The percentages of calves in each group with APP concentrations above the published threshold reference values for $\mathrm{Hp}$, IgM, and $\mathrm{IgG}_{1}$ are shown in Table 2 . In addition, the percentage of calves above the normal threshold for SAA was calculated in this study from the ROC analysis, because a published normal range for newborn calves is lacking for this analyte.

A higher percentage of calves in INF_B had values above the normal thresholds for SAA, Hp, and IgM compared with the 3 other groups, with a significant difference for SAA $(P<0.001)$ and a tendency for Hp $(P<0.1)$. 
Table 1. Mean (SEM) serum amyloid A, haptoglobin, IgM, and $\operatorname{IgG}_{1}$ concentrations $(\mathrm{mg} / \mathrm{L})$ in stillborn calves in the bacterial infection (INF_B), viral or parasitic infection (INF_V/P), traumotocia (TRAUM), and unexplained stillbirth (UNEXPL) groups

\begin{tabular}{lcccc}
\hline Analyte & INF_B & INF_V/P & TRAUM & UNEXPL \\
\hline Serum amyloid A & $53.3(16.5)^{\mathrm{a}, \mathrm{A}}$ & $19.6(10.1)^{\mathrm{B}}$ & $11.9(2.4)$ & $10.7(3.0)^{\mathrm{b}}$ \\
Haptoglobin & $146.7(113.2)^{\mathrm{A}}$ & $5.1(3.5)^{\mathrm{B}}$ & $13.3(6.3)$ & $16.3(6.4)$ \\
IgM & $370.3(144.7)^{\mathrm{A}}$ & $86.1(31.0)^{\mathrm{B}}$ & $81.5(40.4)^{\mathrm{B}}$ & $134.2(49.2)$ \\
IgG $_{1}$ & $136.9(64.7)^{2}$ & $149.4(48.9)$ & $66.1(32.5)$ & $67.1(21.4)$ \\
\hline
\end{tabular}

$\overline{\mathrm{a}, \mathrm{b}}$ Values within a row with different lowercase superscripts differ $(P \leq 0.05)$.

${ }^{\mathrm{A}, \mathrm{B}}$ Values within row with different uppercase superscripts tend to be different $(P>0.05$ but $<0.1)$.

\section{Biomarker Test Characteristics}

The logistic regression model showed that values of SAA and $\operatorname{IgM}$, but not $\mathrm{Hp}$ and $\mathrm{IgG}_{1}$, could significantly differentiate bacterial infection from other COD. The area under curve for SAA was 0.705 (95\% CI: $0.533-0.877 ; P=0.02)$, and for IgM was $0.719(95 \%$ CI: $0.579-0.858 ; P=0.002)$. The ROC curve of SAA is shown in Figure 1. The optimal thresholds, Se, Sp, positive and negative predictive values, likelihood ratio, and odds ratio for SAA and IgM are shown in Table 3.

\section{DISCUSSION}

As expected, higher $\operatorname{IgG}_{1}$ and $\operatorname{Ig} M$ concentrations were found in both infection groups than in the other groups in this study. In the third trimester of pregnancy, the bovine fetus is able to produce antibodies against foreign antigens (Stefaniak et al., 2012; Kelling and Topliff, 2013). In the present study, the serum IgM concentration was higher than that of $\mathrm{IgG}_{1}$ in cases of bacterial infection, contrary to previous results (Sawyer et al., 1973). Immunoglobulin $\mathrm{M}$ is the first class of antibody produced in response to infection. The diagnosis of INF_B in this study was based on bacterial culture, which means that bacterial infection was present at the time of death; hence, it is not surprising that high concentrations of IgM were detected in these calves. Previous studies (e.g., Sawyer et al., 1973) did not differentiate between bacterial and other infection causes and so differences in antibody profiles between studies is not unexpected. The present results are in accordance with those of Ellis et al. (1978), where higher IgM than IgG antibody concentrations were found in aborted fetuses. Higher IgG concentrations would probably be detected in calves that had enough time to survive infection and switch from production of IgM to production of $\operatorname{IgG}_{1}$ (Stavnezer and Amemiya, 2004). The concentration of IgM in calves without infection in the present study (50-150 mg/L) was similar to that reported previously for newborn calves $(110 \mathrm{mg} / \mathrm{L}$; Sawyer et al., 1973). In the present study, the ROC curve analysis showed that the optimal threshold for diagnosis of bacterial infection was much lower $(\geq 52.1 \mathrm{mg} / \mathrm{L})$, with a 6 -times-greater odds of a positive bacterial culture at or above this threshold. However, the low specificity shows that with this threshold, false-positive results will occur. Fewer than half the calves with bacterial infection had an IgM concentration higher than that previously reported for newborn calves (Sawyer et al., 1973). This suggests that in cases with bacterial infection, although high IgM concentrations may be found, low concentrations do not exclude the possibility of a bacterial infection. This is reflected in the relatively low specificity of IgM for the diagnosis of bacterial infection. Although in the present study, the $\operatorname{IgG}_{1}$ concentration was numerically higher in both infection groups compared with the

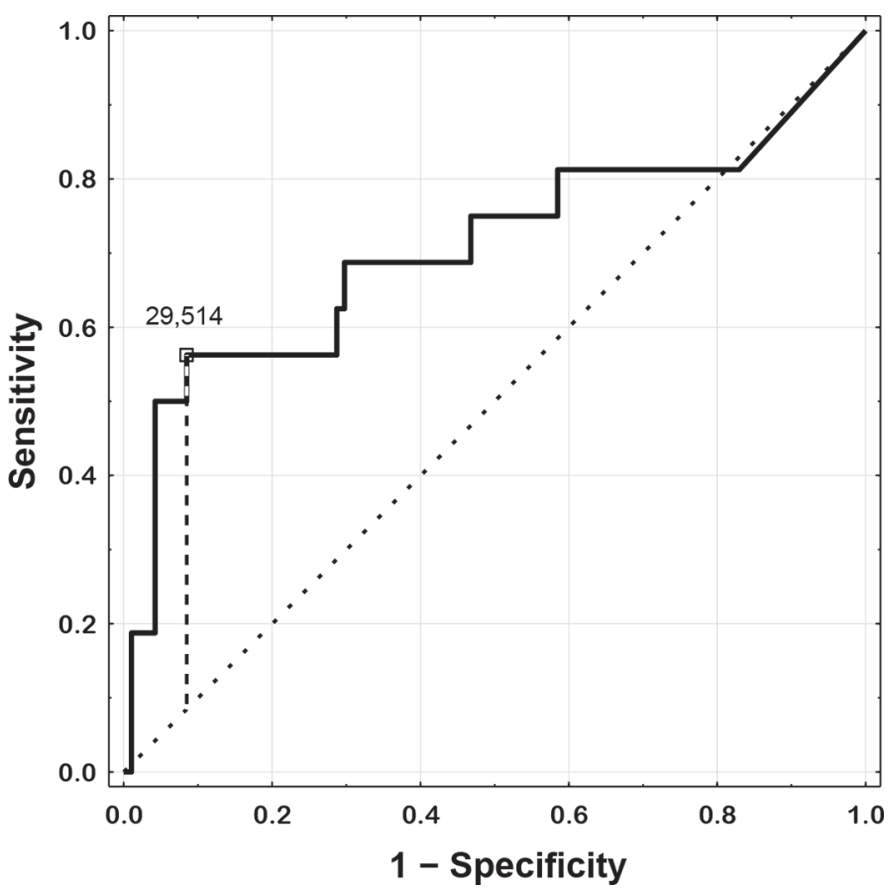

Figure 1. Serum amyloid A (SAA) receiver operating characteristics for discrimination between bacterial infection (INF_B) and other causes of death in stillborn calves. 
Table 2. Percentage of stillborn calves in the bacterial infection (INF_B, $\mathrm{n}=16$ ), viral or parasitic infection $\left(\mathrm{INF} \_\mathrm{V} / \mathrm{P}, \mathrm{n}=31\right.$ ), traumotocia (TRAUM, $\mathrm{n}=22$ ), and unexplained stillbirth (UNEXPL, $\mathrm{n}=41$ ) groups above normal thresholds for serum amyloid A, haptoglobin, $\operatorname{IgM}$, and $\operatorname{IgG}_{1}$

\begin{tabular}{llccrc}
\hline Analyte $^{1}$ & Threshold $(\mathrm{mg} / \mathrm{L})$ & INF_B & INF_V/P & TRAUM & UNEXPL \\
\hline Serum amyloid A*** & $\geq 29.5$ & 56.2 & 12.9 & 9.1 & 4.9 \\
Haptoglobin $\dagger$ & $\geq 100$ & 18.8 & 0 & 4.5 & 4.9 \\
IgM & $\geq 110$ & 43.8 & 19.4 & 22.7 & 22.0 \\
IgG $_{1}$ & $\geq 160$ & 31.2 & 32.3 & 18.2 & 19.5 \\
\hline
\end{tabular}

${ }^{1}$ Reference thresholds for serum amyloid A were calculated from receiver operator characteristic curve analysis in this study; that for haptoglobin was from Richter (1974); and those for IgM and $\operatorname{IgG}_{1}$ were from Sawyer et al. (1973).

*** $P<0.001 ; \dagger P<0.10$ : Pearson's chi-square.

noninfection groups, the percentage of calves with an $\mathrm{IgG}_{1}$ concentration above the normal threshold $(\geq 160$ $\mathrm{mg} / \mathrm{L}$ ) was similar across groups. Therefore, we conclude that for the diagnosis of bacterial infection in stillborn calves, serum IgM concentration is more useful than $\mathrm{IgG}_{1}$ concentration. Calves with traumotocia and with unexplained COD also had detectable but low concentrations of $\operatorname{IgG}_{1}$, which may be seen in normal precolostral calf serum samples (Sawyer et al., 1973).

The inference that bacterial infection in the INF_B group was acute and present at the time of death based on high IgM concentrations was supported by the APP concentrations. Both higher concentrations and more animals with SAA and Hp values above the normal thresholds were seen in INF_B compared with INF_V/P. These results are in agreement with those of Horadagoda et al. (1999), where higher concentrations of SAA and $\mathrm{Hp}$ were reported in animals with acute compared with chronic inflammatory conditions. In that study, 100 and $68 \%$ of animals with acute inflammation had increased SAA and Hp concentrations, respectively, whereas only 54 and $24 \%$ of animals with chronic inflammation had increased SAA and Hp concentrations, respectively. Those authors concluded that SAA is more sensitive to acute inflammatory stimulation than Hp. This is in accordance with our results, where a higher percentage of calves in the group where infection was recent (INF_B) had increased SAA concentrations than had increased Hp concentrations. The highest concentration of $\mathrm{Hp}$ in a stillborn calf with bacterial infection (Trueperella pyogenes) in the current study was $1.8 \mathrm{~g} / \mathrm{L}$. This appears to contradict the suggestion by Alsemgeest et al. (1995) that production of this protein is not fully developed in newborn calves. An elevated SAA concentration was also documented in cases of late aborted and full-term equine fetuses, especially in cases where infectious agents causing multi-organ diseases were detected (Erol et al., 2016). Currently there is no published reference range for SAA in newborn calves. The ROC curve analysis showed that SAA concentrations $\geq 29.5 \mathrm{mg} / \mathrm{L}$ could be used to detect calves with bacterial infection with confidence (odds ratio $=13.8$ ). Given this finding, we propose that this normal range $(0-29 \mathrm{mg} / \mathrm{L})$ be used for SAA in precolostral stillborn calves. Whether this range also applies to precolostral live healthy calves has yet to be established.

Fetal infections with BVDV, SBV, or $N$. caninum occur before the periparturient period. So, even if an acute-phase reaction occurred at the time of infection, it is unlikely that it would be detected at term, as the acute reaction is a short-term response. For example, in calves experimentally infected with Mannheimia haemolytica, the concentrations of SAA and Hp increased within $10 \mathrm{~h}$ after infection (Horadagoda et al., 1994). Although the highest concentrations of both proteins are seen 5 to $8 \mathrm{~d}$ after infection in calves (Heegaard et al., 2000), values return to the normal range within 10 to $15 \mathrm{~d}$ (Ganheim et al., 2003). Therefore, the differences in time lags between infection and death in

Table 3. Optimal thresholds, sensitivity (Se), specificity (Sp), positive and negative predictive values (PPV and NPV), likelihood ratio (LR), and odds ratio (OR) for serum amyloid A and IgM for diagnosis of bacterial infection in stillborn calves

\begin{tabular}{llcccccc}
\hline Protein & Threshold $(\mathrm{mg} / \mathrm{L})$ & Se & Sp & PPV & NPV & LR & OR \\
\hline Serum amyloid A & $\geq 29.5$ & 0.56 & 0.91 & 0.53 & 0.93 & 6.61 & $13.8^{\mathrm{a}}$ \\
IgM & $\geq 52.1$ & 0.75 & 0.68 & 0.29 & 0.94 & 2.35 & $6.4^{\mathrm{b}}$ \\
\hline
\end{tabular}

${ }^{\mathrm{a}} P<0.0001 ;{ }^{\mathrm{b}} P=0.0027$. 
the INF_B and INF_V/P groups most likely accounted for the differences in the APP profile found in these groups.

Calves in the traumotocia group had low concentrations of SAA, which is in accordance with the findings of Alsemgeest et al. (1995) and Orro et al. (2008). Alsemgeest et al. (1995) reported that SAA concentrations were detectable in calves born following different types of obstetrical assistance, and concentrations did not differ between these categories and were independent of the degree of acidosis. However, the effect will probably not be detectable until several hours after birth. Therefore, the suggested threshold generated in this study should be used for blood samples taken as soon as possible after calving. In the present study, $82 \%$ of calves were dead at birth and the remainder within $1 \mathrm{~h}$ of birth. Studies from human medicine (Marchini et al., 2000; Aly et al., 2011) show that hypoxic ischemia and normal birth stimulate significant SAA production in the first day after delivery. This suggests that to detect an in utero APP response to bacterial infection, samples need to be collected from the neonate immediately after birth, before the confounding effects of dystocia and colostrum consumption can alter APP concentrations. Calves in the present study had not consumed colostrum, which can induce an increase in SAA concentrations (Orro et al., 2008). Thus, we conclude that the increases in APP concentrations detected in the INF_B group in the current study were due to pre- or parturient stimulation of the immune-inflammatory response.

Low mean concentrations of the measured variables were recorded in unexplained stillbirths. This suggests that the majority of these calves do not die because of bacterial infections. As their immune-inflammatory profiles were similar to those of calves with viral or parasitic infections and traumotocia, undiagnosed and undiagnosable cases of these conditions (or possibly of undiagnosed and undiagnosable bacterial infections) may theoretically contribute to unexplained stillbirths. This hypothesis is partly supported by the fact that 2 calves from this group had high SAA (98.9 and 81.0 $\mathrm{mg} / \mathrm{L}$ ) and $\mathrm{IgM}(172.2$ and $439.0 \mathrm{mg} / \mathrm{L})$ concentrations, suggesting undiagnosed previous or contemporaneous infection.

This is the first study to show that significant production of APP occurs in the bovine fetus. These high circulatory APP concentrations would not be possible without high concentrations of IL-6, which is the most potent inducer of APP production (Heinrich et al., 1990). Thus, increased concentration of APP in fetal calves indicates that production of this cytokine occurs in fetal calves following bacterial infection. Detection of increased IL-6 concentrations in fetal calves would confirm the link between the putative bovine fetal inflammatory response syndrome (BoFIRS) detected here and FIRS in human fetuses.

The results of this study show that blood SAA and IgM concentrations are significantly associated with pathogenic bacterial infections in stillborn calves. This suggests that these blood tests may be used in 2 ways: first, as rapid screening tests to determine whether further diagnostic testing is warranted, and second, as proxy diagnostic tests in cases where samples for bacterial culture are not optimal or not available.

\section{CONCLUSIONS}

These results demonstrate upregulation of the immuno-inflammatory response in stillborn calves exposed to bacterial infection in utero. This response may be similar to that described as FIRS in human fetuses. The immune-inflammatory response profiles did not differ between calves with viral or parasitic infections and traumotocia. These profiles did not contribute to the diagnosis of unexplained stillbirth. This is the first reported detection of an elevated APP response in stillborn calves.

\section{ACKNOWLEDGMENTS}

This study was supported by funds from the Wroclaw University of Environmental and Life Sciences, Faculty of Veterinary Medicine (Wroclaw, Poland; project no. MWet/279/2012/SC, MWet/754/2013/SC) and Teagasc Moorepark Research Centre (Fermoy, Co. Cork, Ireland; project no. 5902). Publication funding was from the Wrocław Center of Biotechnology, Leading National Research Center (KNOW) program (20142018).

\section{REFERENCES}

Alsemgeest, S. P., F. H. Jonker, M. A. Taverne, H. C. Kalsbeek, T. Wensing, and E. Gruys. 1995. Serum amyloid-A (SAA) and haptoglobin (Hp) plasma concentrations in newborn calves. Theriogenology 43:381-387.

Altman, D. G. 1991. Practical Statistics for Medical Research. 1st ed. Chapman and Hall, London, UK.

Aly, H., Z. Hamed, L. Mohsen, N. Ramy, H. Arnaoot, and A. Lotfy. 2011. Serum amyloid A protein and hypoxic ischemic encephalopathy in the newborn. J. Perinatol. 31:263-268.

Bashiri, A., E. Burstein, and M. Mazor. 2006. Cerebral palsy and fetal inflammatory response syndrome: A review. J. Perinat. Med. 34:5-12.

Bayrou, C., M. M. Garigliany, M. Sarlet, A. Sartelet, D. Cassart, and D. Desmecht. 2014. Natural intrauterine infection with Schmallenberg virus in malformed newborn calves. Emerg. Infect. Dis. 20:1327-1330

Berglund, B., L. Steinbock, and M. Elvander. 2003. Causes of stillbirth and time of death in Swedish Holstein calves examined post mortem. Acta Vet. Scand. 44:111-120. 
Chaiworapongsa, T., R. Romero, J. C. Kim, Y. M. Kim, S. C. Blackwell, B. H. Yoon, and R. Gomez. 2002. Evidence for fetal involvement in the pathologic process of clinical chorioamnionitis. Am. J. Obstet. Gynecol. 186:1178-1182.

Chassagne, M., J. Barnouin, and J. P. Chacornac. 1999. Risk factors for stillbirth in Holstein heifers under field conditions in France: A prospective survey. Theriogenology 51:1477-1488.

Conner, G. H., M. Richardson, G. R. Carter, and J. P. P. Wamukoya. 1977. Immune Responses of the Bovine Fetus. J. Dairy Sci. 60:289-293.

Cooke, R. F., and J. D. Arthington. 2013. Concentrations of haptoglobin in bovine plasma determined by ELISA or a colorimetric method based on peroxidase activity. J. Anim. Physiol. Anim. Nutr. (Berl.) 97:531-536.

Deignan, T., A. Alwan, J. Kelly, J. McNair, T. Warren, and C. O'Farrelly. 2000. Serum haptoglobin: an objective indicator of experimentally-induced Salmonella infection in claves. Res. Vet. Sci. 69:153-158.

Eckersall, P. D., and R. Bell. 2010. Acute phase proteins: Biomarkers of infection and inflammation in veterinary medicine. Vet. J. $185: 23-27$.

Eckersall, P. D., and J. G. Conner. 1988. Bovine and canine acute phase proteins. Vet. Res. Commun. 12:169-178.

EFSA (European Food Safety Authority). 2013. "Schmallenberg" virus: Analysis of the epidemiological data. Supporting Publications EN-429:1-22.

Egyed, L., G. Sassi, J. Tibold, I. Mádl, and O. Szenci. 2011. Symptomless intrauterine transmission of bovine herpesvirus 4 to bovine fetuses. Microb. Pathog. 50:322-325.

Ellis, W. A., E. F. Logan, and J. J. O'Brien. 1978. Serum immunoglobulins in aborted and non-aborted bovine foetuses. Clin. Exp. Immunol. 33:136-141.

Erol, E., C. Jackson, D. Horohov, S. Locke, J. Smith, and C. Carter. 2016. Elevated serum amyloid A levels in cases of aborted equine fetuses due to fetal and placental infections. Theriogenology 86:971-975.

Fourichon, C., F. Beaudeau, N. Bareille, and H. Seegers. 2001. Incidence of health disorders in dairy farming systems in western France. Livest. Prod. Sci. 68:157-170.

Furman-Fratczak, K., A. Rzasa, and T. Stefaniak. 2011. The influence of colostral immunoglobulin concentration in heifer calves' serum on their health and growth. J. Dairy Sci. 94:5536-5543.

Gånheim, C., S. Alenius, and K. Presson Waller. 2007. Acute phase proteins as indicators of calf herd health. Vet. J. 173:645-651.

Gånheim, C., C. Hulten, U. Carlsson, H. Kindahl, R. Niskanen, and K. Presson Waller. 2003. The acute phase response in calves experimentally infected with Bovine Viral Diarrhoea Virus and/or Mannheimia haemolytica. J. Vet. Med. B Infect. Dis. Vet. Public Health 50:183-190.

Gruys, E., M. Van Ederen, S. P. M. Alsemgeest, H. C. Kalsbeek, and T. Wensing. 1993. Acute phase protein values in blood of cattle as indicator of animals with pathological processes. Arch. Lebensmittelhyg. 44:107-111.

Heegaard, P. M. H., D. L. Godson, M. J. M. Toussaintc, K. Tjùrnehùj, L. E. Larsen, B. Viuff, and L. Rùnsholt. 2000. The acute phase response of haptoglobin and serum amyloid A (SAA) in cattle undergoing experimental infection with bovine respiratory syncytial virus. Vet. Immunol. Immunopathol. 77:151-159.

Heinrich, P. C., J. V. Castell, and T. Andus. 1990. Interleukin-6 and the acute phase response. Biochem. J. 265:621-636.

Horadagoda, A., P. D. Eckersall, J. C. Hodgson, H. A. Gibbs, and G. M. Moon. 1994. Immediate responses in serum TNFa and acute phase protein concentrations to infection with Pasteurella haemolytica A1 in calves. Res. Vet. Sci. 57:129-132.

Horadagoda, N. U., K. M. G. Knox, H. A. Gibbs, S. W. J. Reid, A. Horadagoda, S. E. R. Edwards, and P. D. Eckersall. 1999. Acute phase proteins in cattle: Discrimination between acute and chronic inflammation. Vet. Rec. 144:437-441.

Jawor, P., A. Brzozowska, K. Słoniewski, Z. M. Kowalski, and T. Stefaniak. 2016. Acute phase response in the primiparous dairy cows after repeated percutaneous liver biopsy during the transition period. Pol. J. Vet. Sci. 19:393-399. https://doi.org/10.1515/pjvs2016-0049.

Jawor, P., T. Stefaniak, Z. Sołtysiak, S. Dzimira, and M. Bednarski. 2013. Salmonella Enterica Serovar Stanley intrauterine Infection as a cause of brain injury in stillborn calf-case report. Acta Vet. Brno 82:363-367.

Jawor, P., S. Steiner, T. Stefaniak, W. Baumgartner, and A. Rzasa. 2008. Determination of selected acute phase proteins during the treatment of limb diseases in dairy cows. Vet. Med. (Praha) $53: 173-183$

Jones, G. E., and D. L. Mould. 1984. Adaptation of the guaiacol (peroxidase) test for haptoglobins to a microtitration plate system. Res. Vet. Sci. 37:87-92.

Kelling, C. L., and C. L. Topliff. 2013. Bovine maternal, fetal and neonatal responses to bovine viral diarrhea virus infections. Biologicals 41:20-25.

Khodakaram-Tafti, A., and B. O. Ikede. 2005. A retrospective study of sporadic bovine abortions, stillbirths, and neonatal abnormalities in Atlantic Canada, from 1990 to 2001. Can. Vet. J. 46:635-637.

Kindahl, H., B. Kornmatitsuk, K. Königsson, and H. Gustafsson. 2002. Endocrine changes in late bovine pregnancy with special emphasis on fetal well-being. Domest. Anim. Endocrinol. 23:321-328.

Kirkbride, C. A. 1992. Viral agents and associated lesions detected in a 10-year study of bovine abortions and stillbirths. J. Vet. Diagn. Invest. 4:374-379.

Kornmatitsuk, B., E. Dahl, E. Ropstad, J. F. Beckers, H. Gustafsson, and H. Kindahl. 2004. Endocrine profiles, haematology and pregnancy outcomes of late pregnant Holstein dairy heifers sired by bulls giving a high or low incidence of stillbirth. Acta Vet. Scand. 45:47-68.

Marchini, G., V. Berggren, R. Djilali-Merzoug, and L. O. Hansson. 2000. The birth process initiates an acute phase reaction in the fetus-newborn infant. Acta Paediatr. 89:1082-1086.

Mee, J. F. 2013. Why do so many calves die on modern dairy farms and what can we do about calf welfare in the future? Animals (Basel) 3:1036-1057.

Mee, J. F., D. P. Berry, and A. R. Cromie. 2008. Prevalence of, and risk factors associated with, perinatal calf mortality in pasturebased Holstein-Friesian cows. Animal 2:613-620.

Mee, J. F., C. Sanchez-Miguel, and M. Doherty. 2013. An international Delphi study of the causes of death and the criteria used to assign cause of death in bovine perinatal mortality. Reprod. Domest. Anim. 48:651-659.

Mee, J. F., C. Sanchez-Miguel, and M. Doherty. 2014. Influence of modifiable risk factors on the incidence of stillbirth/perinatal mortality in dairy cattle. Vet. J. 199:19-23.

Mee, J. F., and O. Szenci. 2012. Selected pathological causes of bovine stillbirth illustrated with photographic images. Magy. Állatorv. Lapja 134:718-723.

Meyer, C. L., P. J. Berger, K. J. Koehler, J. R. Thompson, and C. G. Sattler. 2001. Phenotypic trends in incidence of stillbirth for Holsteins in the United States. J. Dairy Sci. 84:515-523.

Muskens, J., W. Wouda, T. von Bannisseht-Wijsmuller, and C. van Maanen. 2012. Prevalence of Coxiella burnetii infections in aborted fetuses and stillborn calves. Vet. Rec. 170:260 https://doi. org/10.1136/vr.100378.

Ohmann, H. B. 1981. Immunoglobulin levels in non-aborted and aborted fetuses from Danish herds of cattle. Acta Vet. Scand. $22: 428-434$.

Orro, T., S. Jacobsen, J. P. LePage, T. Niewold, S. Alasuutari, and T. Soveri. 2008. Temporal changes in serum concentrations of acute phase proteins in newborn dairy calves. Vet. J. 176:182-187.

Richter, H. 1974. Haptoglobin bei Haussäugtieren. III. Mitteilung: Der Haptoglobingehalt im Blutplasma und serum von Wiederkäuern und Schweinen unter verschiedenen physiologischen Bedingungen. Arch. Exp. Veterinarmed. 28:505-519.

Romero, R., T. Chaiworapongsa, and J. Espinoza. 2003. Micronutrients and intrauterine infection, preterm birth and the fetal inflammatory response syndrome. J. Nutr. 133:1668S-1673S. 
Sawyer, M., B. I. Osburn, H. D. Knight, and J. W. Kendrick. 1973. A quantitative serologic assay for diagnosing congenital infections of cattle. Am. J. Vet. Res. 34:1281-1284.

Smith, B. I., G. A. Donovan, C. A. Risco, C. R. Young, and L. R. Stanker. 1998. Serum haptoglobin concentrations in Holstein dairy cattle with toxic puerperal metritis. Vet. Rec. 142:83-85.

Smyth, J. A., D. A. Fitzpatrick, and W. A. Ellis. 1999. Stillbirth/ perinatal weak calf syndrome: A study of calves infected with Leptospira. Vet. Rec. 145:539-542.

Smyth, J. A., P. T. McNamee, D. G. Kennedy, S. J. McCullough, E. F. Logan, and W. A. Ellis. 1992. Stillbirth/perinatal weak calf syndrome: Preliminary pathological, microbiological and biochemical findings. Vet. Rec. 130:237-240.

Stavnezer, J., and C. T. Amemiya. 2004. Evolution of isotype switching. Semin. Immunol. 16:257-275.
Stefaniak, T., A. Chełmońska-Soyta, J. Bajzert, P. Jawor, A. Rząsa, and O. Sitnik. 2012. Prenatal and postnatal development of immune system in ruminants. Med. Weter. 68:534-539. [Article in Polish]

Syrjala, P., M. Anttila, K. Dillard, M. Fossi, K. Collin, M. Nylund, and T. Autio. 2007. Causes of bovine abortion, stillbirth and neonatal death in Finland 1999-2006. Acta Vet. Scand. 49(Suppl. I):S3.

Vels, L., C. M. Røntved, M. Bjerring, and K. L. Ingvartsen. 2009. Cytokine and acute phase protein gene expression in repeated liver biopsies of dairy cows with a lipopolysaccharide-induced mastitis. J. Dairy Sci. 92:922-934.

Waldner, C. L., R. I. Kennedy, L. B. Rosengren, C. M. Pollock, and E. T. Clark. 2010. Gross postmortem and histologic examination findings from abortion losses and calf mortalities in western Canadian beef herds. Can. Vet. J. 51:1227-1238. 